\title{
ASPECTOS GENÉTICOS E CLÍNICOS DA FIBROSE CÍSTICA
}

Yasmim Queiroz Santos ${ }^{1}$, Lucieli Boschetti Vinhal ${ }^{2}$; Cristiane Alves da Fonseca do Espírito Santo ${ }^{3}$; Flávio Monteiro Ayres ${ }^{4}$.

1. Bacharel em Fisioterapia e discente no Programa de Mestrado em Ciências Aplicadas a Produtos para a Saúde pela Universidade Estadual de Goiás, Goiânia Goiás yasmimasantos@gmail.com

2. Mestre Profissional em Fisioterapia Intensiva e docente do curso de Fisioterapia da Universidade Estadual de Goiás.

3. Mestre em Biologia e docente dos cursos de Ciências Biológicas e Farmácia da Universidade Estadual de Goiás.

4. Doutor em Controle de Funções Biológicas e docente dos cursos Fisioterapia, Mestrado em Ciências Moleculares e Mestrado em Ciências Aplicadas a Produtos para a Saúde da Universidade Estadual de Goiás.

\section{Recebido em: 08/04/2017 - Aprovado em: 10/06/2017 - Publicado em: 20/06/2017} DOI: 10.18677/EnciBio_2017A122

\begin{abstract}
RESUMO
A Fibrose Cística (FC) é um distúrbio de herança autossômica recessiva causada por milhares de mutações no gene CFTR, cuja gravidade correlaciona-se com a atividade protéica remanescente. A doença ocorre em 1/2.000 a 1/4.000 caucasianos, sendo rara entre africanos e asiáticos. As complicações envolvem o bloqueio de ductos e vias aéreas, além de pneumopatia grave, insuficiência pancreática digestiva com potencial subnutrição crônica, obstrução do cólon pelo íleo meconial e inflamação dos seios nasais. Entre as doenças raras, a FC é a segunda mais prevalente, atrás apenas da anemia falciforme. O tratamento da FC é multidisciplinar baseado em sintomatologia e prevenção sendo importante o conhecimento atualizado da doença por parte de todos os profissionais da área da saúde. Nesse sentido, selecionados os trabalhos científicos mais relevantes na literatura em relação ao tema, e elaborado uma revisão sobre Fibrose Cística abordando os seguintes tópicos: introdução, genética, fisiopatogenia, microbiologia das infecções pulmonares, manifestações clínicas, diagnóstico, tratamento e prognóstico.
\end{abstract}

PALAVRAS-CHAVE: doenças raras, genética, mucoviscosidade

\section{GENETICS AND CLINICAL APPROACH ON CYSTIC FIBROSIS - A LITERATURE REVIEW}

\section{ABSTRACT}

Cystic Fibrosis (CF) is an autosomal recessive disorder caused by thousands of mutations in the CFTR gene, whose severity correlates with the remaining protein 
activity. The disease occurs in $1 / 2,000$ to $1 / 4,000$ Caucasians, is rare among Africans and Asians. Complications involving the blocking ducts and airways, as well as severe lung disease, digestive pancreatic insufficiency with potential chronic malnutrition, colon obstruction by meconium ileus and inflammation of the sinuses. Among the rare diseases, FC is the second most prevalent, behind sickle cell anemia. The treatment of CF is multidisciplinary based on symptoms and prevention is important to the current knowledge of the disease by all health professionals. In this sense, we selected the most relevant scientific papers in the literature regarding the subject and prepared a review of Cystic Fibrosis addressing the following topics: introduction, genetics, pathophysiology, microbiology of lung infections, clinical manifestations, diagnosis, treatment and prognosis.

KEYWORDS: Mucoviscosity, genetics, rare diseases.

\section{INTRODUÇÃO}

A Fibrose Cística (FC), ou doença do beijo salgado, é um distúrbio genético autossômico recessivo (NUSSBAUM et al., 2002), causado por mutações no gene cftr, com uma incidência de aproximadamente 1 em 2.500 caucasianos e uma frequência de portadores de 1 em 25 (DORNELAS et al., 2000; NUSSBAUM et al., 2002; SARAIVA-PEREIRA et al., 2011). Esse gene codifica a proteína CFTR (Cystic Fibrosis Transmembrane Condutance Regulator, do inglês Reguladora de Condutância Transmembrana de Fibrose Cística) (YOUNG, 2007; FARIA et al., 2009).

Em 2014, estima-se que cerca de 2.000 mutações já haviam sido encontradas (MARSON et al., 2015). Há correlação entre as frequências das mutações no gene cftr com a origem étnica e região demográfica dos pacientes com FC. Devido à alta taxa de miscigenação, a população brasileira possui uma grande heterogeneidade alélica do gene cftr, sendo variável também de estado para estado (SARAIVAPEREIRA et al., 2011).

O comprometimento gastrointestinal e pancreático é comum, especialmente, em recém-nascidos com FC. Mais recentemente, o comprometimento respiratório em crianças com $\mathrm{FC}$ tem recebido enfoque observacional com intensa discussão sobre a avaliação prognóstica de progressão precoce da doença. Vale ressaltar, que os sinais e sintomas de progressão são individuais e variáveis (VANDEVANTER et al., 2015).

O diagnóstico pelo teste de suor é considerado padrão ouro. O exame realizado duas vezes em momentos diferentes, com dosagens de cloreto maior que $60 \mathrm{mEq} / \mathrm{L}$, são tidos como determinantes na detecção da FC (DAL'MASO et al., 2013). Este artigo tem como objetivo revisar os mecanismos moleculares e os aspectos clínicos concernentes à FC.

\section{GENÉTICA}

O gene cftr, identificado em 1989 (VOGEL \& MOTULSKY, 2000; NUSSBAUM et al., 2002), possui 27 éxons distribuídos em $250 \mathrm{~kb}$ entre as bandas cromossômicas 7q31-2 (YOUNG, 2007). Ao todo, milhões de polimorfismos foram descobertos nesse gene pelo estudo do genoma humano em busca de alterações genéticas com expressão fenotípica de FC (CORVOL et al., 2015). Concomitante com a identificação do gene cftr, também foi descoberta a primeira mutação relacionada à FC (VOGEL \& MOTULSKY, 2000; NUSSBAUM et al., 2002), que se trata de uma deleção de três nucleotídeos que compõe o códon para fenilanina na 
posição 508 ( $\triangle \mathrm{F} 508)$, conforme descrito no Quadro 1 (NUSSBAUM et al., 2001; SELIMOVIC et al., 2015).

Essa mutação é responsável por $66 \%$ a $80 \%$ dos fenótipos de $\mathrm{FC}$ em todo o mundo (BORTHWICK, 2011; SARAIVA-PEREIRA et al., 2011; PEREIRA et al., 2012), sendo também a mutação mais frequente na população caucasiana com a FC (CARAKUSHANSKY, 2001; FARIA et al., 2009; OTTO, 2013). Segundo a versão provisória do Relatório Brasileiro de Fibrose Cística do ano 2014 - RBFC/2014 (REGISTRO BRASILEIRO DE FIBROSE CÍSTICA, 2014), essa porcentagem no Brasil é estimada em 47,48\%, podendo variar conforme as regiões do país.

QUADRO 1 - Descrição dos alelos selvagem e mutado $\Delta$ F508 no gene cftr.

Alelo Selvagem

\begin{tabular}{lcccccccc}
\hline Códon \# & 504 & 505 & 506 & 507 & 508 & 509 & 510 & 511 \\
\hline Sequência & GA & AAT & ATC & AT드 & $\underline{\text { TTT }}$ & GGT & GTT & TCC \\
\hline Aminoácido & Glu & Asn & lle & lle & Phe & Gly & Val & Ser
\end{tabular}

Alelo Mutado $\Delta$ F508

\begin{tabular}{lllllllll}
\hline Sequência & GA & AAT & ATC & AT- & - T & GGT & GTT & TCC \\
\hline Aminoácido & Glu & Asn & lle & lle & - & Gly & Val & Ser
\end{tabular}

Fonte: adaptada de NUSSBAUM et al. (2001) e SELIMOVIC et al. (2015).

A maioria das quase 2.000 mutações restantes do gene cftr são raras (MARSON et al., 2015), sendo quatro mutações com frequência alélica acima de $1 \%$ entre os indivíduos afetados: p.Gly542X.Gly551Asp, p.Asn1303Lys e p.Trp1282X em estatística mundial (SARAIVA-PEREIRA et al., 2011). A frequência e a distribuição das mutações no cftr variam de acordo com a origem étnica e a localização geográfica dos pacientes com FC (SINGH et al., 2015). A população brasileira, devido à alta taxa de miscigenação, possui uma relevante heterogeneidade alélica do gene, variável também de estado para estado (SARAIVAPEREIRA et al., 2011).

Até 2001, inexistiam estudos epidemiológicos ou de screening neonatal que reportassem a real frequência dos alelos mutados causadores da FC nas diversas regiões do Brasil (CARAKUSHANSKY, 2001). Mais recentemente, houve um crescimento acelerado e benéfico sobre as informações da FC no país. Um exemplo importante desse crescimento é o RBFC/2014 (REGISTRO BRASILEIRO DE FIBROSE CÍSTICA, 2014), com dados relativos às estimativas das frequências genotípicas, descrição das mutações e demais dados de relevância clínica.

O cftr codifica uma proteína de 170 kDa composta por 1.480 aminoácidos (YOUNG, 2007) com função de canal direto para transporte íon cloro através da membrana apical ao interior da célula (PASTERNAK, 2002; SARAIVA-PEREIRA et al., 2011). Não obstante, a sequência primária de aminoácidos dessa proteína indica ENCICLOPÉDIA BIOSFERA, Centro Científico Conhecer - Goiânia, v.14 n.25; p. 1462 2017 
que esta pertence à família $\mathrm{ABC}$ (ATP-binding cassete, do inglês cassete ligante de ATP) de proteínas de transporte (NUSSBAUM et al., 2002), cuja função característica é o transporte de moléculas como: glicídios, peptídeos, fosfato inorgânico, cloreto e cátions de metais (LIMA, 2012). A CFTR é processada no retículo endoplasmático e Golgi por reação de glicosilação e transportada, já dobrada, como proteína glicosilada de membrana (SARAIVA-PEREIRA et al., 2011). Estruturalmente, a proteína é formada por dois domínios repetidos e simétricos, que são compostos por uma região hidrofóbica transmembrana e uma região hidrofílica que possui uma zona de união com ATP (CARAKUSHANSKY, 2001; SARAIVAPEREIRA et al., 2011).

Funcionalmente, a proteína CFTR possui cinco domínios: dois domínios membranares (MSDs), cada um com seis sequências membranares; dois domínios de ligação-(ATP) de nucleotídeos (NBDs); e um domínio regulador (R) com múltiplos sítios de fosforilação. O poro do canal de cloro (Cl-) é formado por 12 segmentos transmembranares. A energia utilizada para transporte de íons é resultante da hidrólise de ATP ligado aos domínios NBDs, sendo que a regulação do canal é mediada, pelo menos em parte, pela fosforilação do domínio R (NUSSBAUM et al., 2002). As mutações do gene cftr são classificadas em diferentes grupos, de acordo com o mecanismo interrompido pela mutação na proteína CFTR (Figura 1).

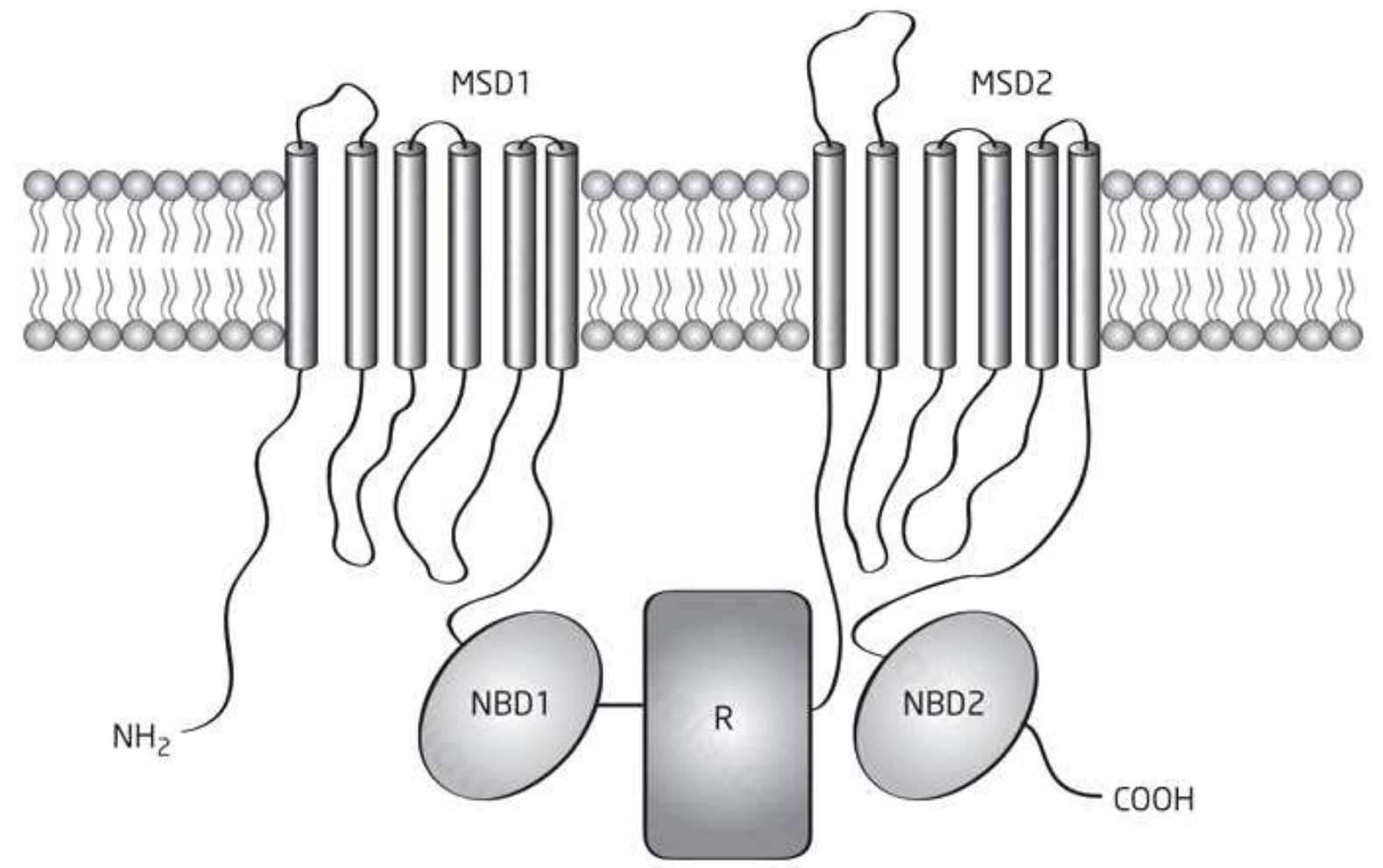

FIGURA 1 - Ilustração esquemática da proteína CFTR, indicando os domínios membranares 1e 2 (MDS1 e MDS2), domínios de ligação-(ATP) de nucleotídeos (NBD1 e NBD2), domínio regulador (R), extremidade amino terminal $\left(\mathrm{NH}_{2}\right)$ e extremidade carboxi terminal $(\mathrm{COOH})$.

Fonte: imagem modificada de http://www.remedicajournals.com/ijcr/BrowseContent/August2011/lmageOpen.axd?aaid=7624, acesso em 03.10.2016. 
Clinicamente, a mutação $\Delta \mathrm{F} 508$ é um marcador genético de relevante valor diagnóstico na população do sudeste brasileiro. Entretanto, essa mutação é menos frequente no Brasil que nos EUA, França e Argentina, porém mais frequente que entre mexicanos (MIRANDA et al., 1993; CABELLO et al., 2003; ALVARES et al., 2004). Essas diferenças ocorrem, pois, a frequência relativa da mutação $\Delta \mathrm{F} 508$ tem considerável variabilidade entre diferentes regiões geográficas e grupos étnicos distintos (CABELLO et al., 2003). Esses resultados suportam que os pacientes brasileiros são tratados conforme os dados divulgados internacionalmente, apesar de apresentarem um perfil étnico e biológico próprio. A implementação de serviços de diagnóstico multidisciplinar é uma das recomendações para que o devido atendimento seja oferecido aos indivíduos acometidos pela FC (Quadro 2) (ALVARES et al., 2004; DALCIN \& SILVA, 2008).

QUADRO 2 - Classes de mutações do gene cftr e as alterações decorrentes.

\begin{tabular}{|c|c|c|c|}
\hline $\begin{array}{l}\text { Classe } \\
\text { da } \\
\text { mutação }\end{array}$ & Evento mutacional & Alteração bioquímica & $\begin{array}{l}\text { Fenótipo } \\
\text { de FC }\end{array}$ \\
\hline$I^{1,2,3,4}$ & $\begin{array}{c}\text { Mutações sem sentido } \\
\text { Mudança no quadro de leitura } \\
\text { Alteração no processamento de } \\
\text { RNA }\end{array}$ & Defeito de síntese & Severo \\
\hline $\mid I^{1,2,3,4}$ & $\begin{array}{c}\Delta \text { F508 } \\
\text { Mutações de sentido trocado }\end{array}$ & $\begin{array}{c}\downarrow \text { glicosilação, dobramento } \\
\text { incorreto e ausência na } \\
\text { membrana celular } \\
\uparrow \text { degradação }\end{array}$ & Clássico \\
\hline IIII, $1,3,5$ & G551D & $\begin{array}{l}\text { Resistência ao AMP cíclico } \\
\downarrow \text { abertura do canal de cloro } \\
\text { Resposta incorreta ao ATP }\end{array}$ & - \\
\hline$I V^{1,4}$ & - & $\begin{array}{l}\downarrow 1 / 3 \text { o fluxo de íons por } \\
\text { defeito de condução }\end{array}$ & Brando \\
\hline $\mathrm{V}^{5}$ & - & $\begin{array}{c}\downarrow \downarrow \text { síntese } \\
\downarrow \text { CFTR na membrana }\end{array}$ & Brando \\
\hline $\mathrm{VI}^{5}$ & - & $\uparrow$ degradação & - \\
\hline
\end{tabular}

Fontes: 'CARAKUSHANSKY, 2001; ${ }^{2}$ NUSSBAUM et al., 2002; ${ }^{3}$ CABELLO, 2011; ${ }^{4}$ SARAIVA-PEREIRA et al., 2011; ${ }^{5}$ DAL'MASO et al., 2013.

Diante do que foi exposto sobre a genética da FC, se a frequência de $\Delta \mathrm{F} 508$ entre pacientes com fibrose cística brasileiros é inferior ao observado no padrão europeu (MIRANDA et al., 1993; CABELLO et al., 2003; ALVARES et al., 2004), logo a FC entre brasileiros é causada por outras mutações, cujo significado prognóstico é variável e requer medidas de acompanhamento compatíveis. 


\section{FISIOPATOGÊNIA}

A FC é classificada como uma doença multissistêmica, crônica e progressiva, evidenciando complexidades no âmbito social, emocional e médico (REIS et al., 2000; SELIMOVIC et al., 2015) que afetam cerca de 70.000 indivíduos no mundo (CORVOL et al., 2015). A identificação da FC foi feita entre 1930 e 1940 quando foi descrita como uma doença da infância, com taxa de mortalidade de $80 \%$ no primeiro ano de vida (ANDERSEN, 1938; REIS et al., 2000).

A FC é caracterizada por um aumento do nível de sódio $(\mathrm{Na}+)$ e cloreto $(\mathrm{Cl}-)$ (SELIMOVIC et al., 2015). Esse aumento gera uma alteração no transporte, e nos fluxos de cloro e água, realizado através das membranas epiteliais apicais de eletrólitos, ocorrendo desidratação extracelular (MARSON et al., 2015). Como consequência de todo mecanismo patológico, há manifestações no funcionamento das estruturas revestidas por essas membranas, sendo estas: pulmões, pâncreas, intestino, árvore hepatobiliar e no trato genital masculino (NUSSBAUM et al., 2002; TRUJILLANO et al., 2015). A cascata de patogênese pulmonar da FC, para melhor entendimento do processo, está ilustrada na Figura 2.

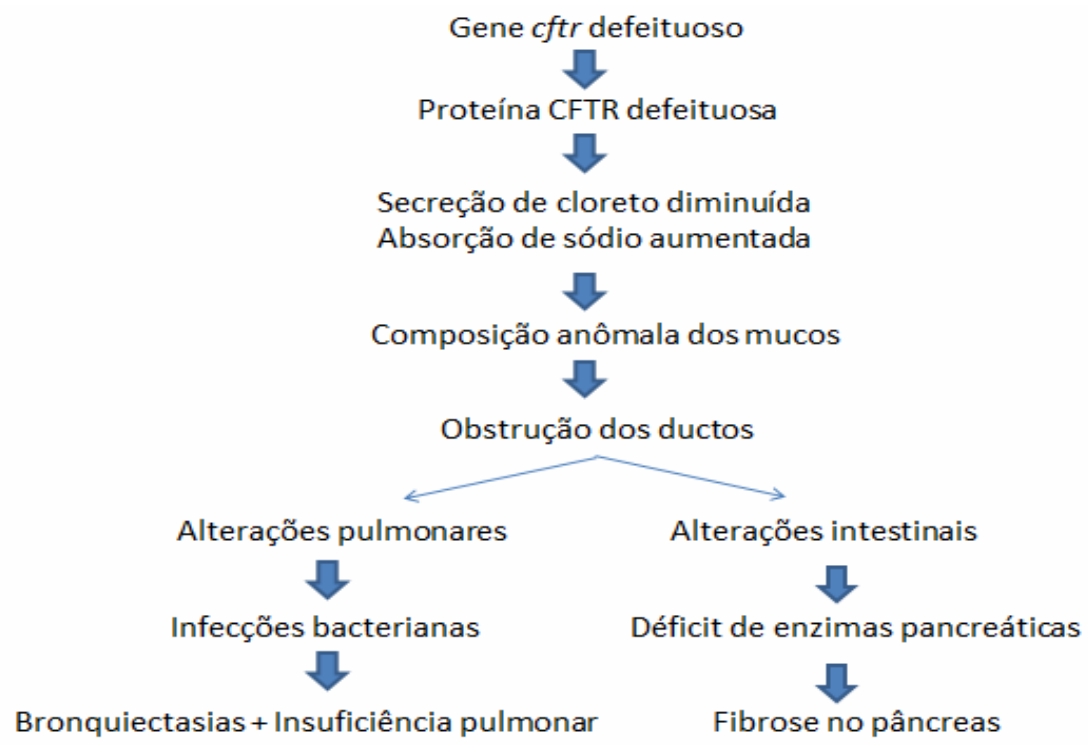

FIGURA 2 - Cascata de patogênese da Fibrose Cística.

Fonte: adaptada de Amaral \& Kuzelmann, 2007; Firmida et al., 2011; Vandevanter et al., 2015

As alterações fisiológicas foram melhor descritas para as glândulas sudoríparas, onde $\mathrm{o} \mathrm{Cl}$ - no ducto da glândula não poderá alcançar a corrente sanguínea, fluindo pela luz através das células do ducto. Portanto, o gradiente que ativaria a entrada de $\mathrm{Na}+$ pela membrana apical estará ausente ou diminuído, levando ao aumento da concentração de $\mathrm{Na}+$ na luz do ducto sudoríparo, em consequência da perda de função da proteína CFTR (NUSSBAUM et al., 2002).

Nas glândulas exócrinas pulmonares, o interior dos canais exócrinos ficam desidratados, como consequência da alteração do fluxo de cloro e de água. Em conjunto, as secreções possuem aspecto viscoso, que favorecem infecções persistentes, comumente por Pseudomonas aeruginosa e Staphylococcus aureus. É 
possível que a alteração iônica dessas secreções reduzam a resistência a patógenos bacterianos e a função antimicrobiana, sendo uma versão para justificar a colonização crônica bacteriana (ANDRADE et al., 2001; FREIRE, 2008).

\section{MICROBIOLOGIA DAS INFECÇÕES PULMONARES}

É possível que a alteração iônica das secreções reduza a resistência a patógenos bacterianos e a função antimicrobiana, sendo uma versão para justificar a alta incidência de colonização crônica bacteriana (ANDRADE et al. 2001; FREIRE, 2008). No ano de 1938, quando a FC foi considerada doença, as infecções eram primariamente associadas a Staphylococcus aureus, eram tratadas com penicilina e reagiam bem clinicamente, emergindo nos anos 50 e sendo considerado o patógeno mais importante na FC.

Apesar da susceptibilidade às frequentes infecções, os pacientes com FC são predispostos a um número limitado de micro-organismos, permanecendo sem explicações para o que de fato determina essa predileção. Sabe-se, no entanto, que existe uma correlação entre a idade do paciente e a predisposição a colonização por um micro-organismo em particular, como ilustrado na Figura 3 (MARQUES, 2011).

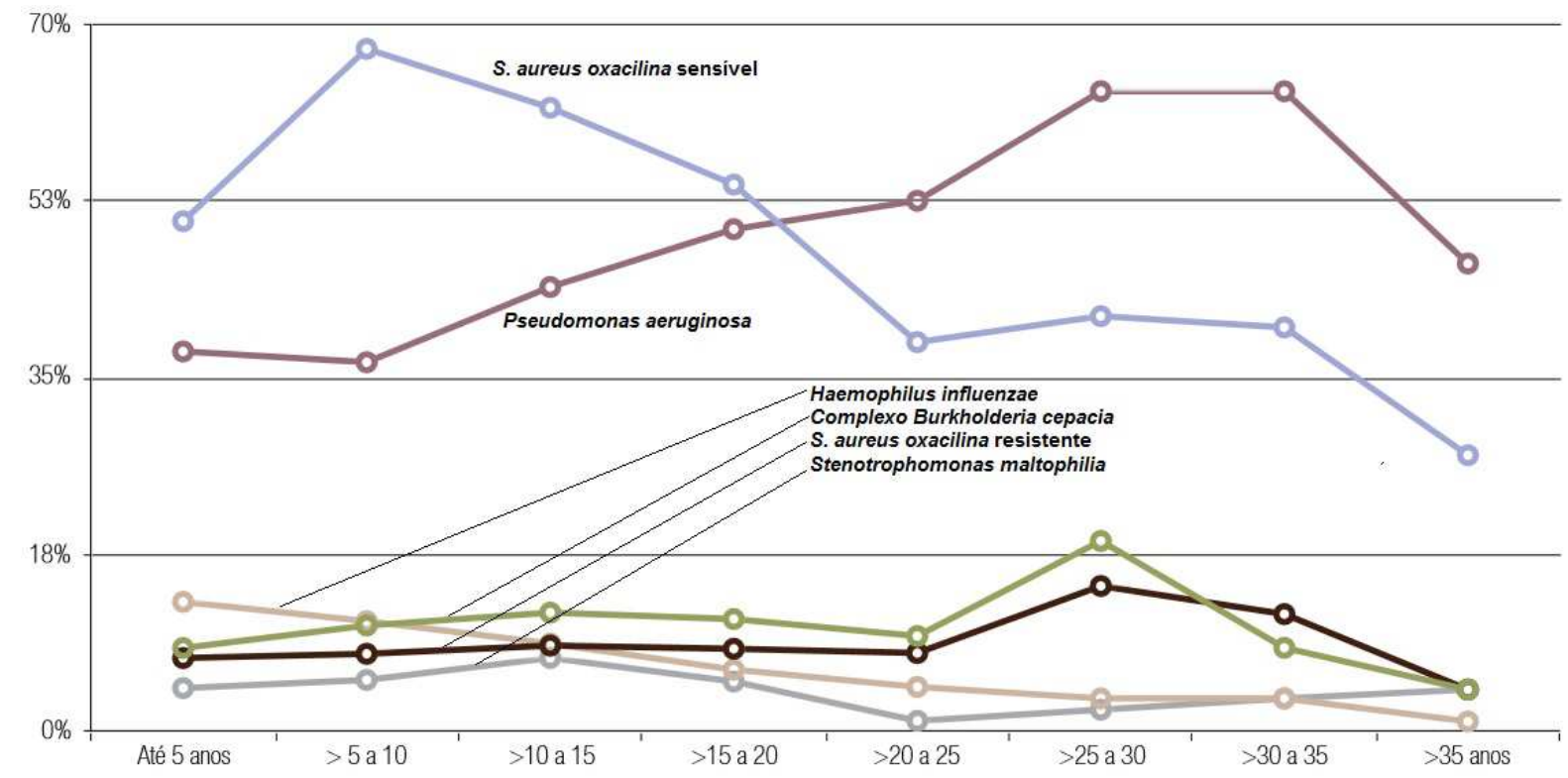

FIGURA 3 - Relação entre microrganismos colonizadores e a idade dos pacientes.

Fonte: Adaptada de REGISTRO BRASILEIRO DE FIBROSE CÍSTICA, 2014.

Pode ser dividido, portanto, em ordem cronológica, a frequência desses micro-organismos com relação à idade. O recém-nascido geralmente não possui micro-organismo colonizador, inicialmente os agentes são predominantemente virais, dois exemplos frequentes: Staphylococcus aureus, e Haemophillus influenzae. A Pseudomonas aeruginosa costuma surgir nos pacientes mais jovens em idade escolar ou adolescente, associadas a um fator mucóide (CASTRO \& FIRMIDA, 2011; MARQUES, 2011).

Outros micro-organismos podem ser encontrados, comumente do grupo de Gram negativos não fermentadores, são: Complexo Burkholderia cepacia, Strenotrophomonas e Achromobacter xylosidans. O maior desafio atual para os 
laboratórios de microbiologia clínica é reconhecer os micro-organismos, mesmo que não estejam reconhecidos como verdadeiros patógenos, pois a correta caracterização influencia de forma direta nas estratégias de tratamento e controle da infecção (CASTRO \& FIRMIDA, 2011; MARQUES, 2011).

\section{MANIFESTAÇÕES CLÍNICAS}

A FC tem sintomas variáveis, tal como o início. Há casos em que apresenta no período neonatal, e casos em que o indivíduo permanece anos assintomático. Entre os sintomas mais comuns estão: tosse crônica, diarreia crônica e desnutrição (REIS \& DAMASCENO, 1998). Por ser multissistêmica, as manifestações clínicas podem ser classificadas de acordo com o local de acometimento e alteração fisiopatológica.

Sistema respiratório - o acometimento das vias respiratórias é o aspecto mais crítico da FC, ocorre em mais de 95\% dos pacientes, e frequentemente a intensidade está relacionada ao prognóstico final (REIS, 1998). No aspecto anatomofisiológico, as vias áreas são responsáveis pela proteção dos locais de troca gasosa. No sistema respiratório o muco faz parte do mecanismo de defesa próprio do indivíduo, nesse caso o envolvimento respiratório na FC inicia-se com a produção e retenção de secreções espessas e viscosas dentro dos bronquíolos. As alterações do muco são secundárias a outros eventos como, por exemplo, alteração da condutância dos íons cloreto e colonização crônica (PRADO, 2011; CASTRO, FIRMIDA, 2011). A alteração mais frequente em vias áreas superiores são a rinossinusite e a polipose nasal, sendo a prevalência de 92 a $100 \%$ e 7 a 67\%, respectivamente (CASTRO \& FIRMIDA, 2011). A FC não provoca alterações na ultraestrutura ciliar, responsável pela mobilização das secreções nas vias áreas superiores e inferiores, protegendo da entrada de partículas e germes (II DIRETRIZES BRASILEIRAS NO MANEJO DA TOSSE CRÔNICA, 2006), também conhecida como clearence mucociliar, porém nos pacientes com FC ela encontra-se diminuída (CASTRO \& FIRMIDA, 2011).

Os sinais e sintomas do comprometimento respiratório são variados, dentre estes: hipersecreção de forma espessa, muitas vezes, purulento; tosse crônica persistente; sibilância e roncos relacionados a obstrução crônica; diâmetro anteroposterior do tórax abaulado; colapsos ou atelectasias; hiperinsuflação pulmonar; pneumotórax espontâneo; fibrose pulmonar; dispneia; cor pulmonale; abaulamento do arco pulmonar; em fases mais avançadas da doença podem apresentar hemoptise (REIS, 1998; FIRMIDA et al., 2011).

Sistema digestivo - a principal alteração do sistema digestivo é a insuficiência exócrina do pâncreas (REIS, 1998). A disfunção de 99\% da CFTR ocasiona comprometimento do pâncreas, por alteração na passagem de ânions e redução do conteúdo hídrico, e acidez, da secreção pancreática, podendo levar a obstrução dos ductos e fibrose no pâncreas. Esse processo determina a progressão do acometimento pancreático (FIRMIDA et al., 2011). Os pacientes no caso de comprometimento pancreático têm como sintomatologia: diarreia crônica, fezes volumosas, amarelo palha, brilhantes, gordurosas e fétidas. As manifestações gastrointestinais em geral são secundárias a alteração pancreática. A obstrução canalículos pancreáticos por tampões mucosos impedem a liberação das enzimas para o duodeno, determinando má digestão de gorduras, proteínas e carboidratos (ROSA et al., 2008). A forma mais precoce da FC no sistema digestivo é o íleo meconial, com prevalência de 15 a 20\% em recém-nascidos, mas apenas essa 
mesma porcentagem tem FC quando apresenta íleo meconial (REIS, 1998). A CFTR é o único canal de cloro na membrana celular apical, do intestino, portanto, a disfunção compromete a secreção de cloreto para o lúmen intestinal, como consequência o material fecal fica espesso (FIRMIDA et al., 2011).

Déficit de crescimento - quando há oferta nutricional suficiente e o lactente não consegue ganhar peso, provavelmente, será por problemas de má absorção. No caso de desnutrição protéica calórica sugere-se a presença de FC.

Suor hipertônico - uma das referências mais antigas da FC, diz respeito a um dizer folclórico norte-europeu, apresentado no Almanaque de Canções e Jogos para Crianças: "Infeliz da criança que, quando beijada na fronte, apresente sabor salgado. Ela está fadada a morrer precocemente" (WELSH, \& SMITH, 1995).

Outras manifestações atípicas - cirrose hepática biliar focal, litíase biliar, hipertensão portal com esplenomegalia e varizes esofageanas, doença celíaca, doença de crohn e pancreatite crônica (REIS, 1998).

\section{DIAGNÓSTICO}

Diagnóstico pré-implantacional - envolve o estudo de tecido embrionário, coletado por punção em caso de fertilização assistida (SARAIVA-PEREIRA et al., 2011).

Diagnóstico pré-natal - inicialmente, ocorre sob a forma de aconselhamento genético, no qual pais portadores, por exemplo, tem $25 \%$ de chances de terem os dois alelos mutados de cftr transmitidos para a prole. As quase 2.000 mutações alélicas podem ser identificadas em homozigose ou heterozigose por testes genéticos, bem como o diagnóstico de FC pode ser excluído pela detecção de alelos selvagens (CARAKUSHANSKY, 2001).

Diagnóstico neonatal - um teste de triagem genética universal da FC é inaplicável até que $95 \%$ das mutações sejam identificadas, o que é de difícil alcance devido ao elevado número de mutações já identificadas no gene cftr (CARAKUSHANSKY, 2001; NUSSBAUM, et al., 2002).

No Brasil, as Diretrizes Clínicas na Saúde Suplementar (ASSOCIAÇÃO MÉDICA BRASILEIRA, 2011) sobre o diagnóstico e tratamento da FC recomendam o "teste do pezinho" para verificar o nível da imunotripsina reativa (IRT) como triagem de FC em todos os recém-nascidos. A IRT é uma enzima pancreática que frequentemente se eleva como consequência secundária da FC. Esse método, entretanto, é sujeito a resultados falso negativos e os resultados positivos não são específicos para FC (CARAKUSHANSKY, 2001; NUSSBAUM, et al., 2002; GONÇALVES, 2013). Por isso, os casos com resultado positivo devem ser confirmados pelo teste do suor, considerado padrão ouro de diagnóstico (DAL'MASO et al., 2013). O teste de suor consiste na administração transdérmica de pilocarpina por iontoforese para estimular a transpiração, seguida pela coleta do suor e quantificação do cloro por colorimetria e sódio por fotometria de chama. O critério para realização do teste do suor em neonatos é apresentar, pelo menos, duas semanas de vida ou peso > 2kg (CABELLO et al., 2003; FOLESCU \& COHEN, 2011; SELIMOVIC et al., 2015).

O teste da medida da diferença de potencial nasal (DPN) mede in vivo, o lado interno e externo da célula epitelial da mucosa nasal, para determinar a diferença de potencial existente, o qual é comparável a diferença de potencial da mucosa brônquica. $\mathrm{O}$ resultado correlaciona com o transporte de íons através da membrana 
celular, especialmente os íons sódio e cloro, sendo que o lado mucoso é mais negativo em comparação com o lado intracelular. $O$ valor de referência normal é em torno de $-20 \mathrm{mV}$. Na FC, esses valores estão cerca de duas vezes mais negativos, sendo possível ser utilizado como um teste complementar de diagnóstico (PROCIANOY, 2011).

Em regiões com elevada frequência da mutação $\Delta F 508$, a detecção de um alelo heterozigoto com essa mutação em associação com significativa elevação da IRT sugerem fortemente o diagnóstico de FC. Nesse caso, o diagnóstico é confirmado pelo teste do suor. Os casos de detecção de homozigose da mutação $\triangle$ F508 permitem 0 imediato diagnóstico de FC (CARAKUSHANSKY, 2001; NUSSBAUM et al., 2002).

Diagnóstico além do período neonatal - tem como procedimento inicial a investigação clínica de manifestações típicas pulmonares e/ou gastrointestinais e/ou história típica da doença em parente próximo, seguida pelo teste do suor. Resultados com concentração de cloreto no suor acima de $60 \mathrm{mEq} / \mathrm{l}$ permitem o diagnóstico da FC, enquanto os valores normais de referência variam entre 45 a $60 \mathrm{mEq} / \mathrm{l} . \mathrm{E}$ (CARAKUSHANSKY, 2001; RIBEIRO et al., 2002).

Entretanto, os dados epidemiológicos sobre FC nas regiões sul e sudeste do Brasil revelam que 13\% dos pacientes com FC apresentaram dosagens de cloro no suor inferior a $60 \mathrm{mEq} / \mathrm{l}$, enquanto os valores reduzidos do cloro em pacientes com FC no resto do mundo são próximos a $2 \%$ (ALVARES et al., 2004). Esse contexto caracteriza o diagnóstico genético molecular da FC como uma ferramenta de diagnóstico precoce eficaz, mesmo quando os exames laboratoriais convencionais não são conclusivos. Apesar de pouco sensível, devido ao grande número de mutações, o diagnóstico genético molecular é altamente preciso e recomendado quando disponível (CARAKUSHANSKY, 2001; RIBEIRO et al., 2002; DAL'MASO, 2013).

Exames complementares - adicionalmente, a avaliação das funções pancreática e pulmonar, análise microbiológica periódica das secreções respiratórias, exames de imagem por radiografia e tomografia são úteis para investigar o grau de progressão, bem como o prognóstico dos pacientes com FC (FOLESCU \& COHEN, 2011).

\section{TRATAMENTO E PROGNÓSTICO}

A FC é uma doença multissistêmica, crônica e progressiva. Apesar do avanço no conhecimento sobre essa doença, esta não possui cura, sendo recomendado o acompanhamento em centros de referência com equipe multidisciplinar composta, por exemplo, pelo Pneumologista, Fisioterapeuta, Nutricionista, Psicólogo, Enfermeiro e Assistente Social (REIS et al., 2000; PRADO, 2011; SELIMOVIC et al., 2015). Em geral, as terapias disponíveis se restringem a atenuação dos sintomas, sendo ainda limitadas (NETO, 2009). A adesão ao tratamento, como quanto aos diversos aspectos multiprofissionais descritos nesta revisão, é importante e contribui para o aumento da expectativa de vida, passando de dois anos de vida em 1950, para 30 a 40 nos dias de hoje (RIBEIRO et al., 2002; PRADO, 2011). O segundo fator importante é o diagnóstico precoce, com o tratamento sendo realizado antes dos danos pulmonares (ROSA et al., 2008). 


\section{CONSIDERAÇÕES FINAIS}

Podemos concluir após essa revisão geral que, a fibrose cística é uma doença com alterações moleculares de alta complexidade e curso clínico sistêmico variável. É possível identificar a necessidade de um tratamento específico e individualizado para um maior sucesso no prognóstico. Nesse caso, o conhecimento de toda equipe multiprofissional acerca da doença em todos seus aspectos (genético, fisiológico, afecções bacterianas, diagnóstico e tratamento) pode garantir uma abordagem mais adequada e eficiente para esses pacientes.

\section{AGRADECIMENTOS}

YQS foi aluna de IC/PIVIC da Universidade Estadual de Goiás. FMA recebeu auxílio financeiro de Bolsa de Incentivo ao Pesquisador - BIP, concedida pela Universidade Estadual de Goiás. Esta pesquisa é parte do projeto PROEXT2013 (SIGProj No: 116463.480.94044.13042012), fomentado pelo Ministério da Educação/Secretaria de Educação Superior.

\section{REFERÊNCIAS}

ALVAREZ, A. E.; RIBEIRO, A. F.; HESSEL, G.; BERTUZZO, C. S.; RIBEIRO, J. D. Fibrose cística em um centro de referência no Brasil: característica clínicas e laboratoriais de 104 pacientes e sua associação com o genótipo e a gravidade da doença. Jornal de Pediatria, v. 80, n. 5, p. 371 - 379, 2004. Disponível em: <http://dx.doi.org/10.2223/1221> DOl:http://dx.doi.org/10.2223/1221

AMARAL, M. D., KUZELMANN, K. Molecular targeting of CFTR as a therapeutic approach to cystic fibrosis. Trends in Pharmacological Science. v. 28, n. 7, p. 33441, 2007. Disponível em: < http://dx.doi.org/10.1016/j.tips.2007.05.004> DOl: http://dx.doi.org/10.1016/j.tips.2007.05.004

ANDERSEN, D. H. Cystic fibrosis of the pancreas and its relation to celiac disease: a clinical and pathological study. American Journal of Diseases of Children, v. 56, p. 344-99, $1938 . \quad$ Disponível em: <http://archpedi.jamanetwork.com/article.aspx?articleid=1177974> doi:10.1001/archpedi.1938.01980140114013.

ANDRADE, E. F.; FONSECA, D. L. O.; ABREU E SILVA, F. A.; MENNA-BARRETO S. $S$. Avaliação evolutiva da espirometria na fibrose cística. Jornal de Pneumologia. v. 27, n. 3, p. 130-6, 2001. Disponível em: <http://www.scielo.br/pdf/\%0D/jpneu/v27n3/9224.pdf>

ASSOCIAÇÃO MÉDICA BRASILEIRA/AGÊNCIA NACIONAL DE SAÚDE SUPLEMENTAR. Fibrose Cística Diagnóstico e Tratamento. Diretrizes Clínicas na Saúde Suplementar, 2011. Disponível em em: <http://diretrizes.amb.org.br/ans/fibrose_cistica-diagnostico_e_tratamento.pdf>

BORTHWICK, L. A., BOTHA, P., VERDON, B., BRODLIE, M. J., GARDNER, A., BOURN, D., JOHNSON, G.E., GRAY, M.A., FISHER, A.J. Is CFTR-delF508 really absent from the apical membrane of the airway epithelium? PLoS One. v. 6, n. 8, 
e23226, 2011, Disponível em: <http://dx.doi.org/10.1371/journal.pone.0023226> . doi: 10.1371/journal.pone.0023226

CABELLO, G. M. K.; CABELLO, P. H.; ROIG, S. R. S.; FONSECA, A.; CARVALHO, E. C. D. FERNANDES, O. Rastreamento da fibrose cística usando-se a análise combinada do teste de IRT neonatal e o estudo molecular da mutação $\Delta \mathrm{F} 508$. Jornal Brasileiro de Patologia e Medicina Laboratorial. v. 39, n. 1, p. 15-20, 2003. Disponível em: <http://dx.doi.org/10.1590/S1676-24442003000100004>

CABELLO, G. M. K. Avanços da genética na fibrose cística. Revista do Hospital Universitário Pedro Hernesto. v. 10, n. 4, p. 36-45, 2011. Disponível em: $<$ http://revista.hupe.uerj.br/audiencia_pdf.asp?aid2=71\&nomeArquivo=v10n4a04.pdf $>$

CARAKUSHANSKY, G. Doenças genéticas em pediatria. Rio de Janeiro: Guanabara Koogan, p. 228-237, 2001

CASTRO, M. C. S.; FIRMIDA, M. C. O tratamento na Fibrose Cística e suas complicações. Revista do Hospital Universitário Pedro Ernesto, Vol. 10, n. 4, 2011.

CORVOL, H.; BLACKMAN, S.M.; BOE"LLE,P; GALLINS, P.J.; PACE, R. G.; STONEBRAKER, J. R.; et al. Genome-wide association meta-analysis identifies five modifier loci of lung disease severity in cystic fibrosis. Nature Communications, $\mathrm{n}$. 6, v. $\quad 8382 . \quad$ Disponível em: <https://www.ncbi.nlm.nih.gov/pmc/articles/PMC4589222/> DOI: 10.1038, 2015.

DAL'MASO, V. B.; MALLMANN; L.; SIEBERT, M.; SIMON, L.; PEREIRA, M. L. S.; DALCIN, P. T. R. Diagnostic contribution of molecular analysis of the cystic fibrosis transmembrane conductance regulator gene in patients suspected of having mild or atypical cystic fibrosis. Jornal Brasileiro de Pneumologia., v.39, n.2, p.181-189, 2013. Disponível em: <http://www.scielo.br/pdf/jbpneu/v39n2/1806-3713-jbpneu-392-0181.pdf> http://dx.doi.org/10.1590/S1806-37132013000200009

DALCIN, P. T. R.; SILVA, F. A. A. Fibrose cística no adulto: aspectos diagnósticos e terapêuticos. Jornal Brasileiro de Pneumologia. v.34 n.2, p. 107-17,2008. Disponível em: <http://www.scielo.br/pdf/jbpneu/v34n2/en_v34n2a08.pdf>

DORNELAS, E. C.; FERNANDES, M. L. M.; GALVÃO, L. C.; SILVA, G. A. Estudo do quadro pulmonar de pacientes com fibrose cística. Jornal de Pediatria,v. 76, n. 4, p. 295-290, 2000. Disponível em: http://www.jped.com.br/conteudo/00-76-04295/port.pdf

FARIA, E. J.; FARIA, I. C. J.; RIBEIRO, J. D.; RIBEIRO, A. F.; HESSEL, G.; BERTUZZO, C. S. Associação entre os polimorfismos dos genes MBL2, TGF- $\beta 1$ e CD14 com a gravidade da doença pulmonar na fibrose cística*. Jornal Brasileiro de Pneumologia, v. 35, n. 4, p. 334 - 342, 2009. Disponível em: <http://www.scielo.br/pdf/jbpneu/v35n4/en_v35n4a07.pdf> http://dx.doi.org/10.1590/S1806-37132009000400007 
FIRMIDA, M. C., MARQUES, B. L., DA COSTA, C. H. Fisiopatologia e manifestações clínicas da fibrose cística. Revista do Hospital Universitário Pedro Hernesto. v. 10, n. 4, 2011. Disponível em: <http://revista.hupe.uerj.br/detalhe_artigo.asp?id=70>

FOLESCU, T. W.;. COHEN, R. W. F. Avanços no Diagnóstico da Fibrose Cística Visão Crítica? Revista do Hospital Universitário Pedro Ernesto. v. 10, n. 4, p. 5965. 2011. Disponível em: <http://revista.hupe.uerj.br/detalhe_artigo.asp?id=73>

FREIRE, I. D; ABREU E SILVA, F. A.; ARAÚJO, M. A. Comparação entre provas de função pulmonar, escore de Shwachman-Kulczycki e escore de Brasfield em pacientes com fibrose cística. Jornal Brasileira de Pneumologia, v. 34, n. 5, p. 280287, 2008. Disponível em: <http://www.scielo.br/pdf/jbpneu/v34n5/en_v34n5a06.pdf> http://dx.doi.org/10.1590/S1806-37132008000500006

GONÇALVES, L. C. S. Variações de sequência do gene cftr na população pediátrica portuguesa. Mestrado em biologia celular e molecular. Porto, 2013. Disponível em: <http://www.remedicajournals.com/ijcr/BrowseContent/August2011/ImageOpen. axd?aaid=7624>

II DIRETRIZES BRASILEIRAS NO MANEJO DE TOSSE CRÔNICA, Jornal Brasileiro de Pneumologia. v.32, n.6, p. 403-446, 2006. Disponível em: <http://dx.doi.org/10.1590/S1806-37132006001000002>

LIMA, P. A. V. Novas Estratégias De Diagnóstico da Fibrose Cística. Farmácia, Centro Universitário Estadual da Zona Oeste, p. 17 - 28, 2012. Disponível em: <http://www.uezo.rj.gov.br/tccs/ccbs/paola-ameixoeira.pdf>

MARQUES, E. A. Perfil Microbiológico na Fibrose Cística. Revista do Hospital Universitário Pedro Ernesto, v. 10, n. 4, p. 23-35, 2011. Disponível em: $<$ http://revista.hupe.uerj.br/detalhe_artigo.asp?id=69>

MARSON, F.A. L., HORTENCIO, T. D. R AGUIAR,K. C. A., RIBEIRO,J. D. CYFIUC GROUP. Demographic, clinical, and laboratory parameters of cystic fibrosis during the last two decades: a comparative analysis. BMC Pulmonary Medicine, v. 15, n.3, 2015.

MIRANDA, A. B., LLERENA JUNIOR, J., DALLALANA, L. T., MOURA-NETO, R. S., SUFFYS, P. N., DEGRAVE, W. M. Use of PCR for the determination of the frequency of the dF508 mutation in Brazilian cystic fibrosis patients. Memórias do Instituto Oswald Cruz. v. 88, n. 2, p. 309-12, 1993. Disponível em: <http://dx.doi.org/10.1590/S0074-02761993000200022>

NETO, N. L. Fibrose cística enfoque multidisciplinar. Santa Catarina: Secretaria de Estado da Saúde, p. 588, 2009. Disponível em: http://www.acam.org.br/images/livro/fcem2aed.pdf

NUSSBAUM, R.L., MCINNES, R. R., WILLARD, H. F. THOMPSON e THOMPSON. Genética Médica. Rio de Janeiro: Guanabara Koogan, p. 49, 2002. 
OTTO, P. A.; NETTO, R. C. M.; OTTO, P. G. Genética médica. Roca, São Paulo, p. 214-215, 2013.

PASTERNAK, J.J. Genética Molecular Humana - Mecanismos das Doenças Hereditárias. Editora Manole, São Paulo, 2002.

PEREIRA, F. F. L.; FIGUEIREDO, R.; PEDROSA, J. F.; ALVIM, C. G.; CAMARGOS, P. A. M.; IBIAPINA, C. C. Escores clínicos e diagnósticos por imagem na fibrose cística, Revista de Medicina Minas Gerais, v. 22, n. 22, Supl. 7, p. 32 - 39, 2012. Disponível em: <http://rmmg.org/artigo/detalhes/642>

PRADO, S. T. O papel da fisioterapia na Fibrose Cística. Revista Hospital Universitário Pedro Ernesto, v. 10, n. 4, p. 118-25, 2011. Disponível em: $<$ http://revista.hupe.uerj.br/detalhe_artigo.asp?id=78>

PROCIANOY, E. F. A. Diferença de potencial nasal: um novo teste para diagnóstico de fibrose cística. Revista Hospital de Clínicas de Porto Alegre, v. 31, n. 2, p. 125130, $2011 . \quad$ Disponível em: <http://seer.ufrgs.br/index.php/hcpa/article/view/21577/12886>

REGISTRO BRASILEIRO DE FIBROSE CÍSTICA - RBFC/2014, Grupo Brasileiro de Estudo de Fibrose Cística, p. 1 - 34 2014. Disponível em: <www.gbefc.org.br>

REIS, F. J. C.; OLIVEIRA, M. C. L.; PENNA, F. J.; OLIVEIRA, M. DAS G. R.; OLIVEIRA, E. A.; MONTEIRO, A. P. A. F. Quadro clínico e nutricional de pacientes com fibrose cística: 20 anos de seguimento no HC-UFMG. Revista da Associação Médica Brasileira, v. 46, n. 4, p. 325-30, 2000. Disponível em: <http://dx.doi.org/10.1590/S0104-42302000000400031>

REIS, F. J. C.; DAMASCENO, N. Fibrose Cística. Jornal de Pediatria, v. 74, Supl 2, p. 76-94, 1998. Disponível em: <http://www.scielo.br/scielo.php?script=sci_nlinks\&ref=000121\&pid=S0104$1169200300010001000009 \&$ Ing=pt.

RIBEIRO, J. D; RIBEIRO, M. A. G. O.; RIBEIRO, A. F. Controvérsias na fibrose cística - do pediatra ao especialista. Jornal de Pediatria. v. 78, Supl. 2, p. 171-186, 2002. Disponível em: <http://www.scielo.br/pdf/jped/v78s2/v78n8a08.pdf>

ROSA, F. R.; DIAS, F. G.; NOBRE, L. N.; MORAIS, H. A. Fibrose cística: uma abordagem clínica e nutricional. Revista de Nutrição, v. 21, n. 6, p. 725-737, 2008.

SARAIVA- PEREIRA, M. L.; FITARELLI-KIEHL, M.; SANSEVERINO, M. T. V. A Genética na fibrose cística. Revista Hospital de Clínicas de Porto Alegre, v. 31, n. 2, p. 160-167, 2011. Disponível em: <http://seer.ufrgs.br/hcpa/article/view/20905>

SELIMOVIC, A.; MUJICIC, E.; MILISIC, S.; MESIHOVIC-DINAREVIC, S.; DZINOVIC, A.; CENGIC, S. et al. Analysis of Cystic Fibrosis in Federation of Bosnia and Herzegovina. Medical Archives. v. 69, n. 4, p. 222-225, 2015. Disponível 
em:<https://www.ncbi.nlm.nih.gov/pmc/articles/PMC4610639/pdf/MA-69-222.pdf> doi: 10.5455/medarh.2015.69.222-225

SINGH, M.; REBORDOSA,C.; BERNHOLZ, J.; SHARMA, N. Epidemiology and genetics of cystic fibrosis in Asia: In preparation for the next-generation treatments. Oficial Journalof the Asian Pacific Society of Respirology, v. 20, p.1172- 1181, 2015. Disponível em: <http://onlinelibrary.wiley.com/doi/10.1111/resp.12656/full> DOI: 10.1111/resp. 12656

TRUJILLANO, D.; WEISS, M. E. R.; KÖSTER, J.; PAPACHRISTOS, E. B.; WERBER, M.; KANDASWAMY, K. K.; et al. Validation of a semiconductor next-generation sequencing assay for the clinical genetic screening of CFTR. Molecular Genetics \& Genomic Medicine, v. 3, n. 5, p. 396 - 403, 2015. Disponível em: <http://onlinelibrary.wiley.com/doi/10.1002/mgg3.149/epdf> DOI: 10.1002/mgg3.149

VANDEVANTER, D. R.; KAHLE, J. S.; O'SULLIVAN, A. K.; SIKIRICA, S.; HODGKINS, P. S. Cystic fibrosis in young children: A review of disease manifestation, progression, and response to early treatment. Journal of Cystic Fibrosis, v. 15, n. 2, p. $147-57,2015$. Disponível em: $<$ http://dx.doi.org/10.1016/j.jcf.2015.09.008 >

VOGEL, F.; MOTULSKY, A.G. Genética Humana - Problemas e abordagens. Editora Guanabara Koogan, Rio de Janeiro, 2000.

WELSH, M. J.; SMITH, A. E. The genetic defects underlying this letal disease have now been shown to eliminate or hobble a critical channel through which a constituent of salt enters and leaves cells. Scientific American Brasil, v. 52, n. 9,1995.

YOUNG, I.D. Genética Médica. Editora Guanabara Koogan, Rio de Janeiro, p. 92, 2007. 